Association of Arab Universities

Journal of Engineering Sciences

مجلة اتحاد الجامعات العربية للاراسات والبحوث الهندسية

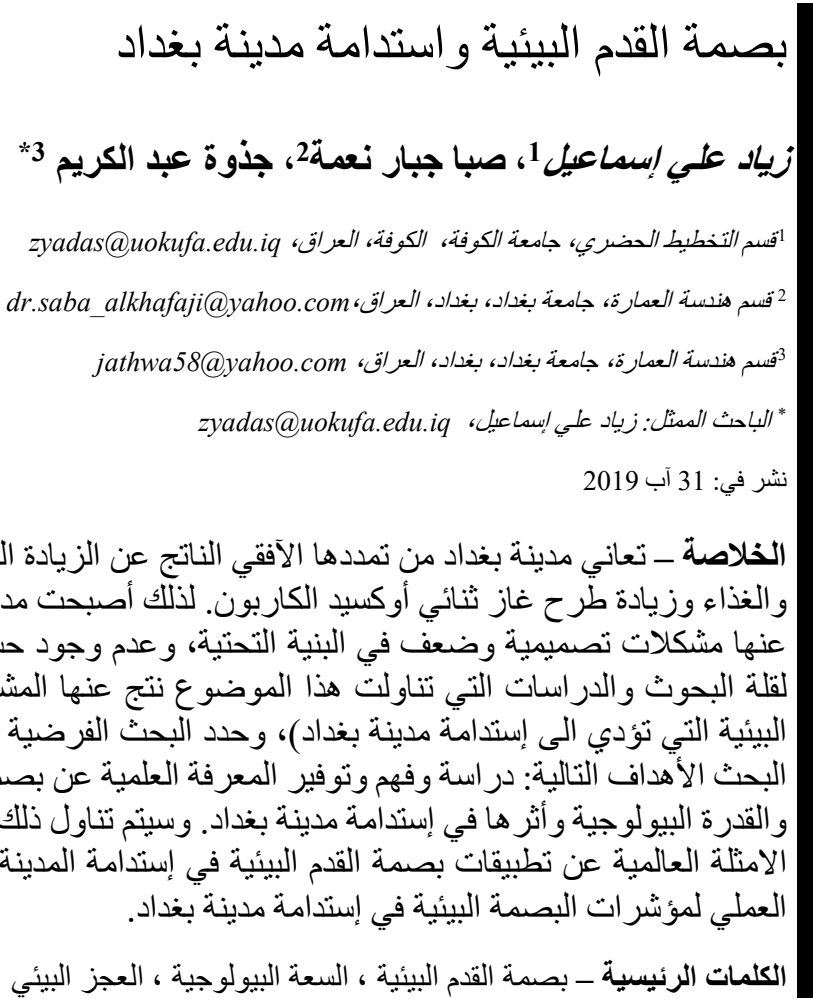

الكلمات الرئيسية ـ بصمة القدم البيئية ، السعة البيولوجية ، العجز البيئي ، الاستهلاك المستدام.

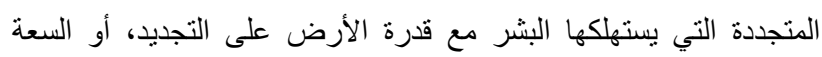

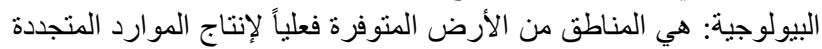

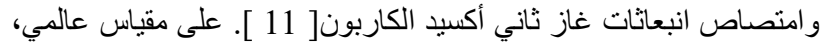

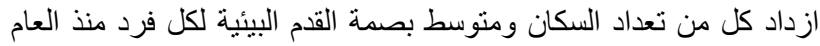

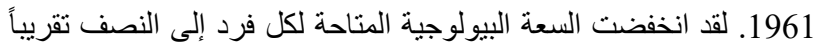

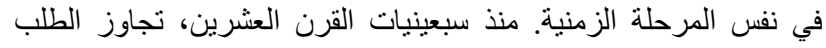

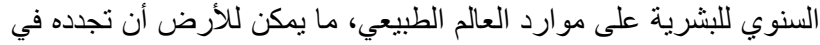
كل عام. كما موضح في الثكل لانس عل 1.

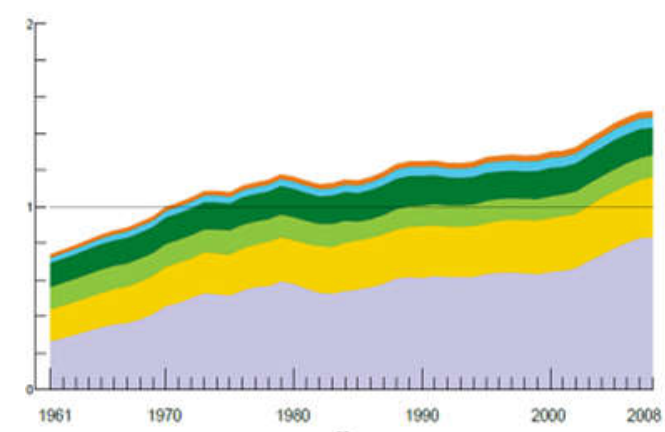

الثكل (1): تجاوز البصمة و عدد كواكب الأرض اللازمة للعيش [17]

\section{1}

تمنل مدينة بغداد أكبر تجمع للسكان في العراق، ويمارسون نشاطاتهم بداخلها،

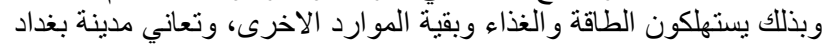

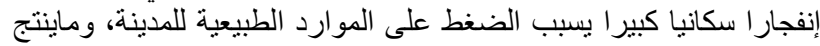

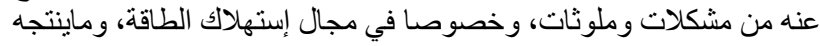

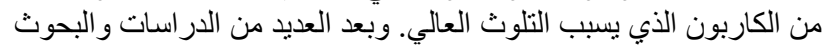

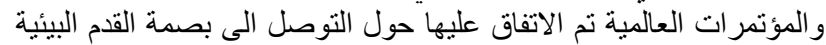

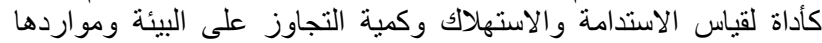

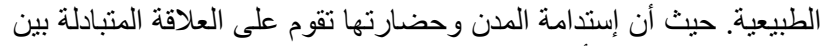

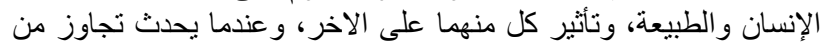

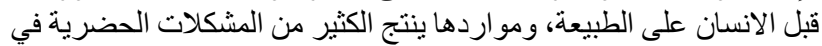

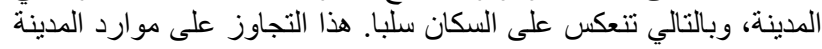

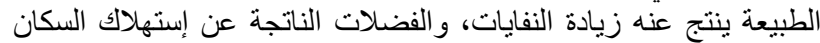

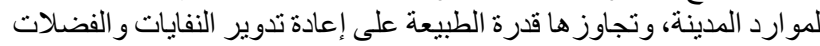

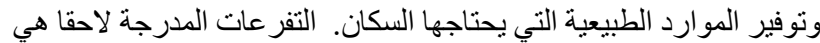

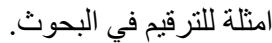

\section{2. مفهوم بصمة القدم البيئية}

هنالك عدة تعاريف لبصمة القدم البيئية منها : بصمة القدم البيئية هي قياس

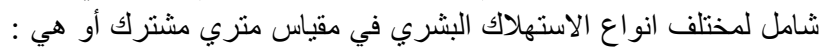

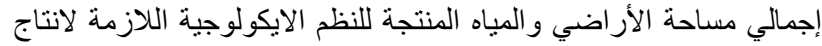

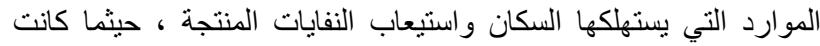

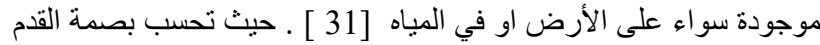
البيئية معدل الطلب البشري على الأنظمة الحيوية عن طريق مقارنة الموارد 


\section{مكونات بصمة القدم البيئية}

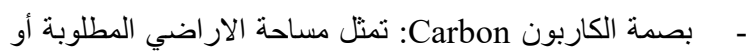

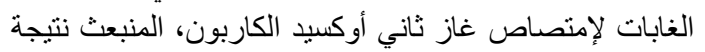

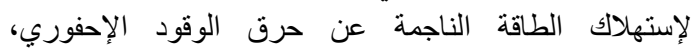

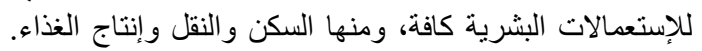

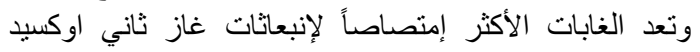

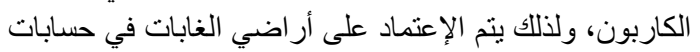

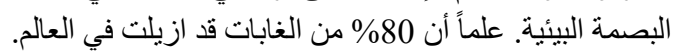

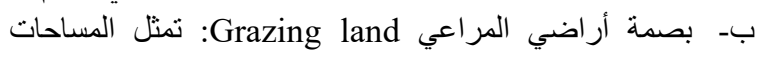

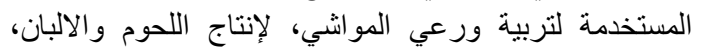
ولتوفير العلف للحيو انات. ح- الغابات Forest land: تمثل مساحة الغابات اللازمة لإنتاج

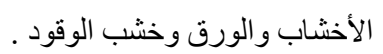

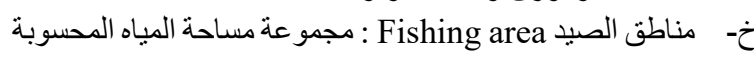
للإنتاج الأولي لصيد الأسماك وتربية الأحياء المائية ( المناطق الصناه الحئ الساحلية في الأساس).

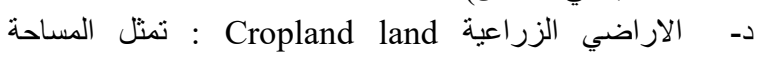

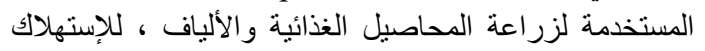

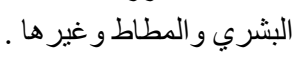

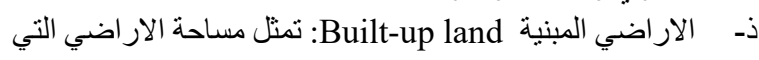
تغطيها البنية التحتية البشرية ، بما في ذلك السكن ، والئ والمباني

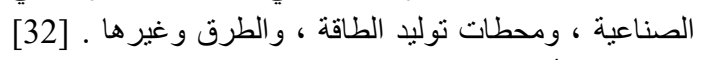

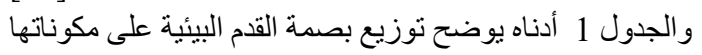

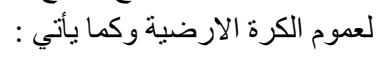

جدول (1): توزيع بصمة القدم البيئية على مكوناتها لعموم الكرة الارضية .[13]

\begin{tabular}{|c|c|}
\hline النسبة المئوية لكل نوع & 2.2 مكونات بصمة القدم البيئية \\
\hline$\% 54$ & أر اضي إنتاج الطاقة (الكاربون ) \\
\hline$\% 8$ & 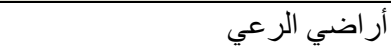 \\
\hline$\% 10$ & أر اضي الغابات \\
\hline$\% 22$ & أر اضي المحاصيل الزر اعية \\
\hline$\% 4$ & مناطق الصبد \\
\hline$\% 2$ & المناطق المبنية \\
\hline$\% 100$ & المجموع \\
\hline
\end{tabular}

\section{حسابات بصمة القدم البيئية الرياضية}

يمكن التوصل لحسابات البصمة البيئية عبر المعادلات الآتية وكما يأتي:

$$
E F=D / Y
$$

يمثل EF بصمة القدم البيئية وD الطلب السنوي على منتج ما، أما Y فهو

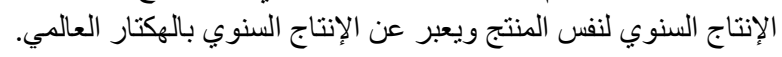

يتضح مما تقدم ان بصمة القدم البيئية هي اداة تستخدم لمعرفة

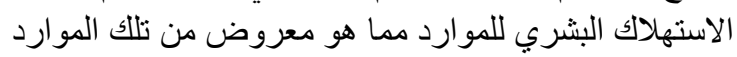

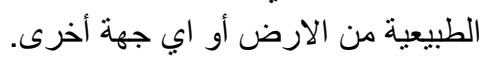

\section{السعة البيولوجية (الحيوية)}

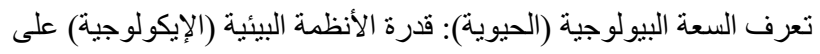

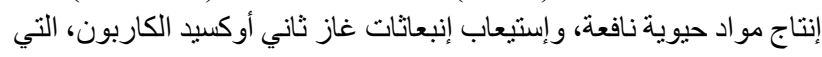

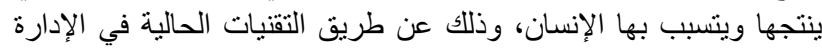

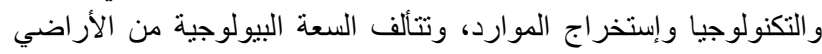

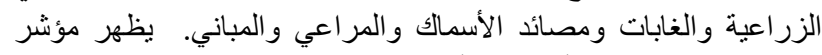

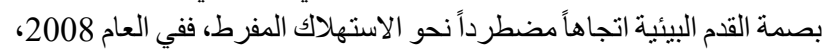
بلغت سعة الأرض البيولوجية (12 مليار هكتار عالمي)، أو (1.8 هكتار

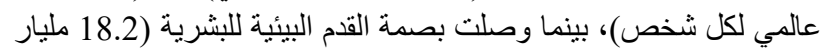

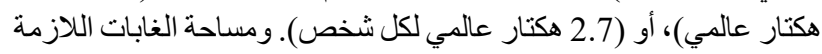

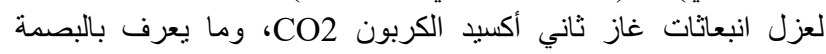

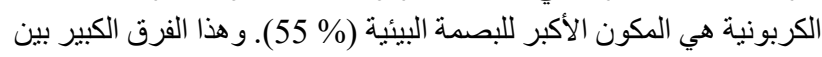

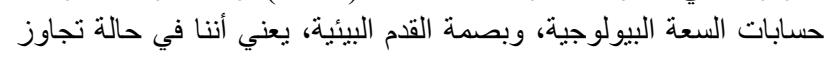

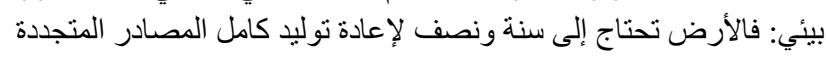

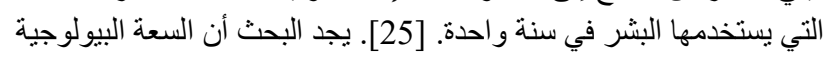

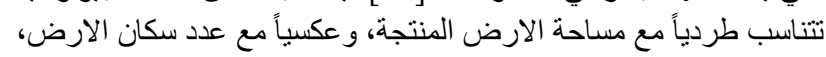

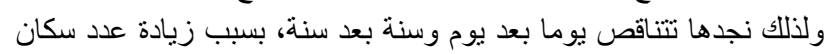

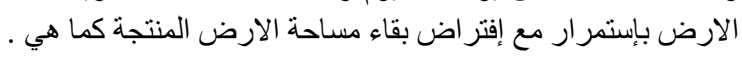

\section{2}

عندما تتجاوز بصمة القدم البيئية السعة البيولوجية المتاحة، تعد الدولة في

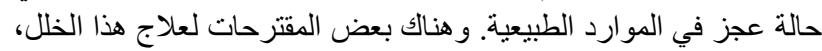

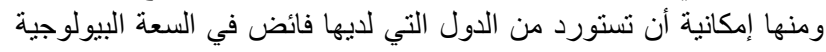

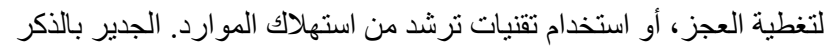

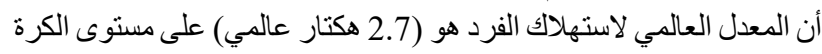
الأرضية. ولتقدير العجز أو الفائض يتم طرح الإن الاستهلاك (بصمة القدم البيئية)

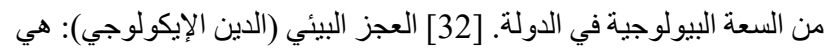

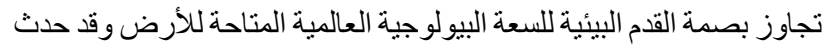

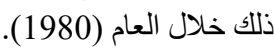

هناك عدة أسباب تؤدي إلى العجز البيئي وهي:

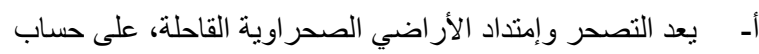

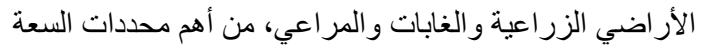

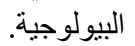

ب- الإعتماد الكلي على الوقود الإحفوري، أي إمدادات النفط و الغاز

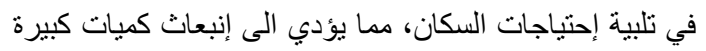

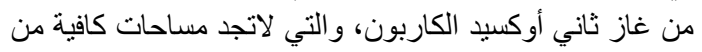

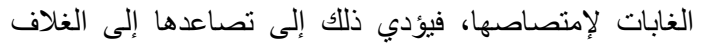

الجوي، والذي يسهم بنسبة كبيرة بزيادة بصدة القدام البئي البئية.

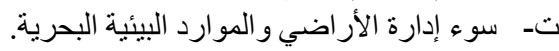

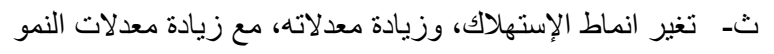

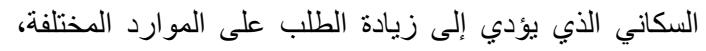

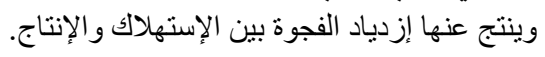

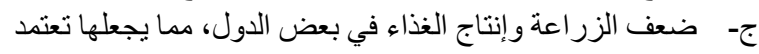

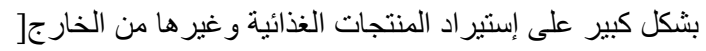




\section{عامل التكافؤ ER}

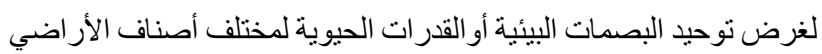

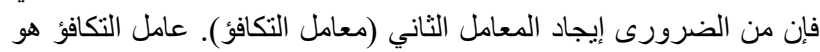

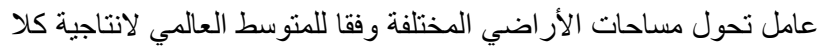

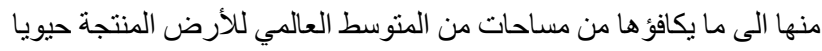

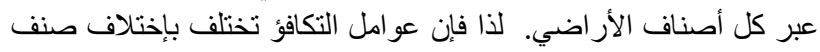

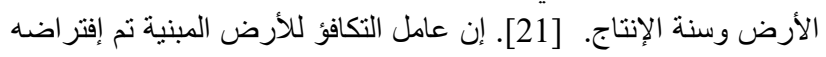

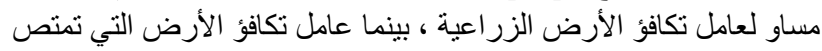

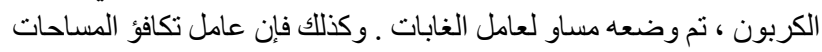

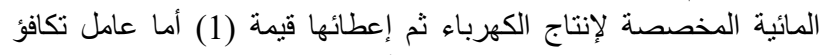

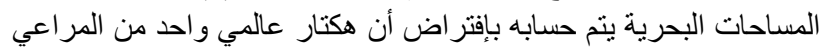

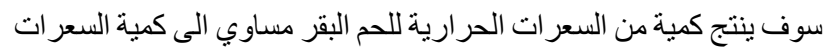

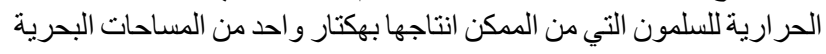

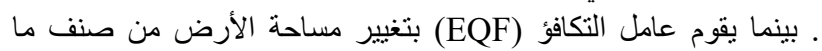

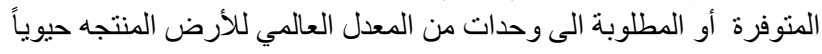

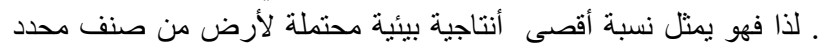

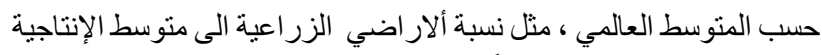

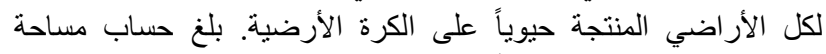

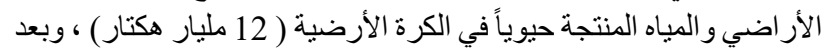

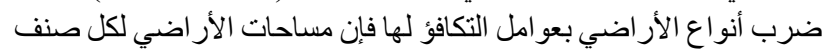

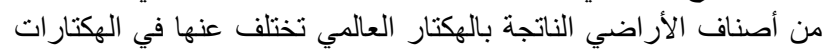
الفعلية.

جدول (2): قيم معامل التكافؤ للأنو اع المكونة لبصمة القدم البيئية [21]

\begin{tabular}{|c|c|}
\hline $\begin{array}{c}\text { معامل التكافؤ بالهكتار العالمي ( EQF ) } \\
\text { ( })\end{array}$ & نوع الارض \\
\hline 2.51 & أراضي المحاصيل الزراعية \\
\hline 1.26 & الغابات \\
\hline 0.46 & اراضي الرعي \\
\hline 0.37 & اراضي المياه \\
\hline 2.51 & الاراضي المبنية \\
\hline 1.26 & الكاريون \\
\hline
\end{tabular}

بعد التطرق الى مفهوم ومكونات و المعادلات الرياضية لبصمة القدم البيئية،

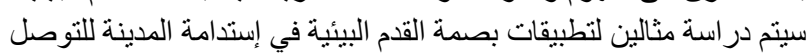

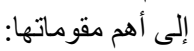

\section{3}

\section{بصدة القدم البيئية كأداة للتصديم الحضري على المستوى المحلي

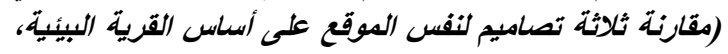

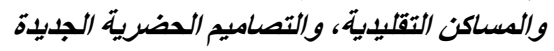

سيتم تحليل بيئي مقارن لثناثة تصاميم للموقع نفسه لاثبات بصمة القدم البيئية،

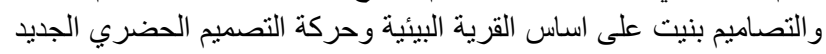

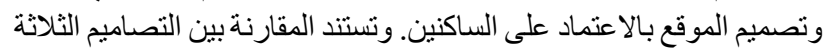

تتأثر قيمة حساب معادلة بصمة القدم البيئية بعاملين سيأتي شرحهما لاحقا

أـ- عامل الإنتاج بF (Yield Factor) هو مقارنة معدل الإنتاج

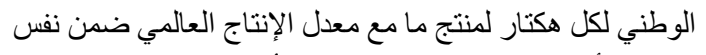

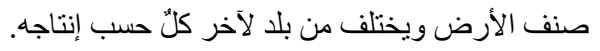

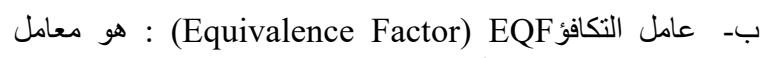
التكافؤ لإستخدام الأرض و الذي يقوم بحساب الإنتاجية النسبية

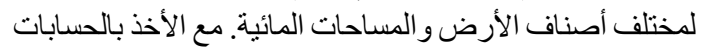
هذين العاملين تصبح معادلة بصمة القدم البيئية كالآتي:

$$
E F=P / Y n * Y F * E Q F
$$

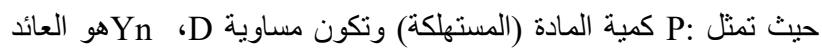

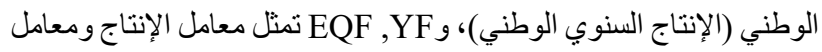
التكافؤ على التو الي للبلا وحسب الإن صنف الأرض. ، وض.

\section{5}

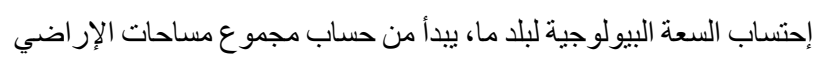

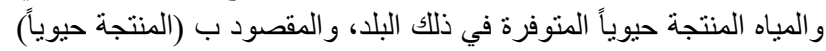

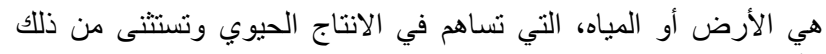

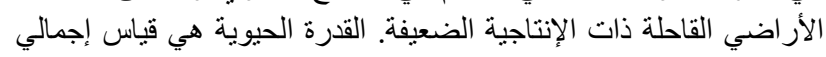

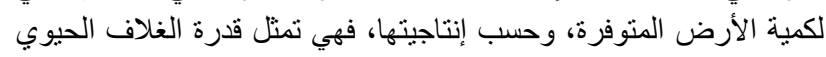

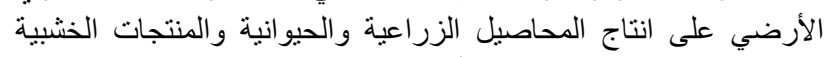

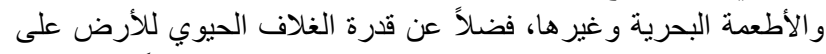

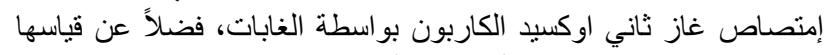

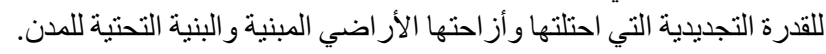

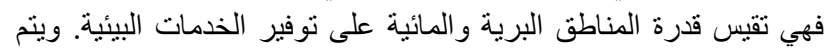
إحتساب القدرة الحيوية BC لبلد ما ولصنف معين من الأرض ولئة وكالآتي:

$$
B C=A * Y F * E Q F
$$

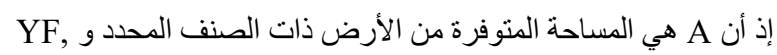

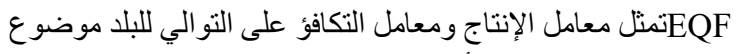

الدر اسة وحسب صنف الأرض [13:

\section{YF 2.6}

عامل الإنتاج YF هو نسبة معدل الإنتاج الوطني الى معدل الإنتاج العالمي

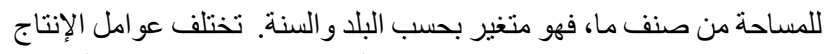

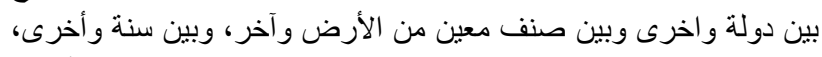

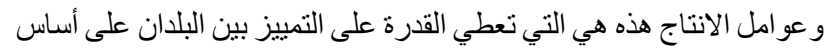

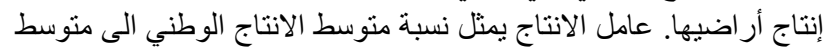

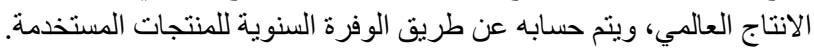

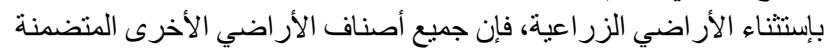

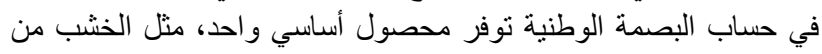

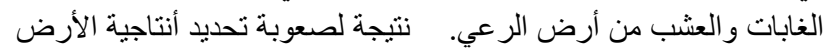

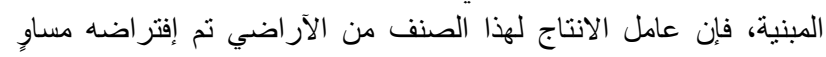

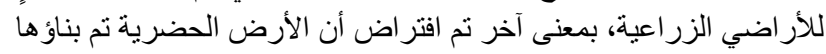

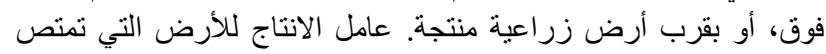

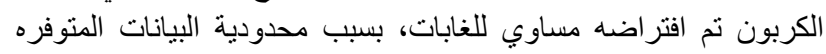

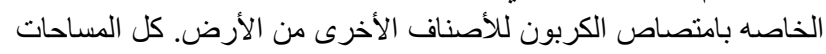

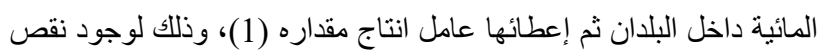

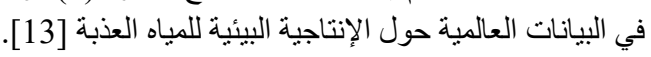


الثكل (4) الخطة المقترحة لروز هيل وو اضضح فيهها أن المساكن تحتل

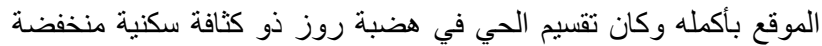

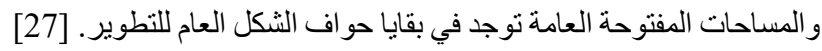

3.1.5 حيث اعتمد على مجمو عتين من الحسابات الأولى هي التقديرات الإجمالية

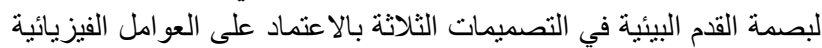

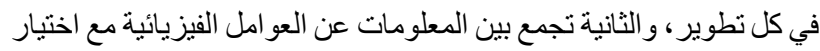

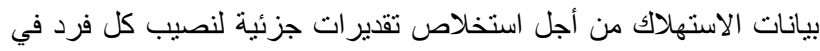
البدائل الثلاثة [37]. تشمل المعلومات الثلات المادية لحساب البصمة البيئية،

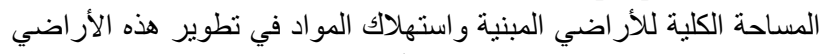

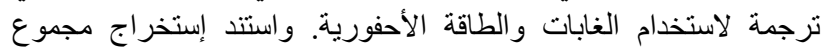

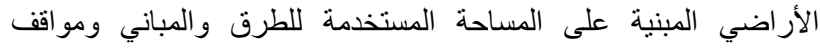

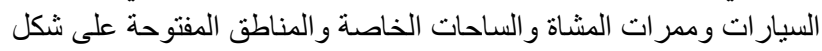
منتزهات أو بقايا الار اضي على حافة منطقة التطوير [31].

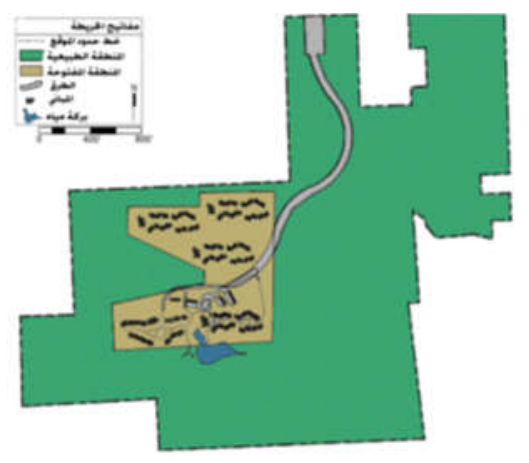

الثكل (2): مخطط تطوير القرية البيئية في أيثاكا [28]

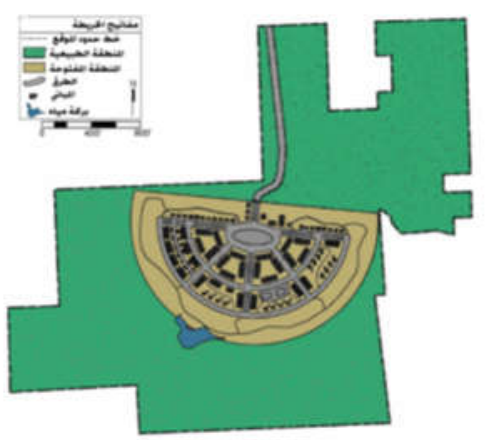

الثكل (3): مخطط تطوير أوكسبريدج الجديدة [28]

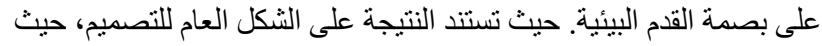

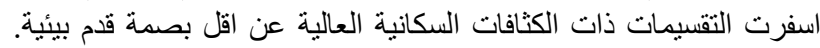

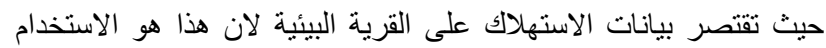

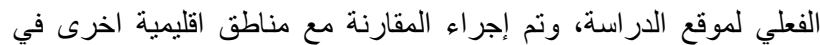

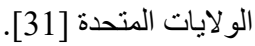

3.1.1

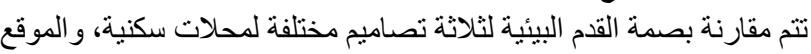

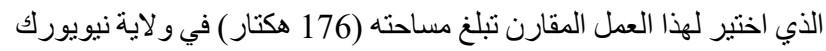

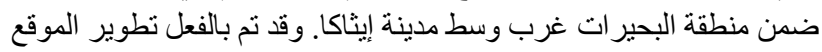

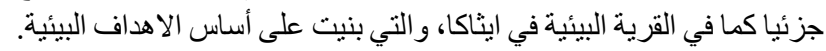

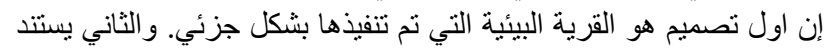

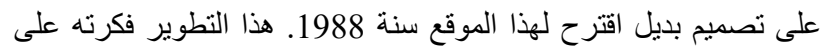

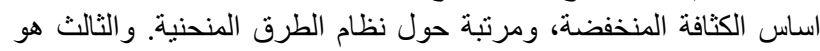

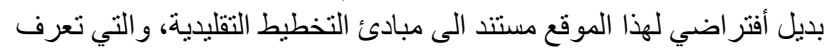

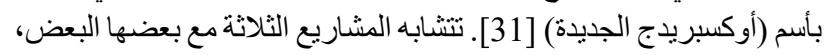

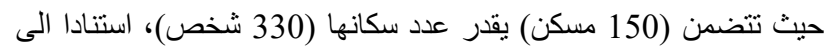
متوسط (2.2 شخص في الأسرة).

3.1.2

صممت وبنيت القرية البيئية في إيثاكا كمجتمع حساس إلى الئى الأرض، حسب البـان

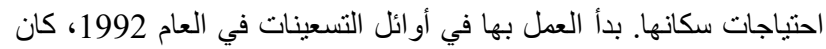

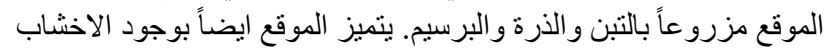

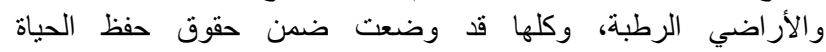

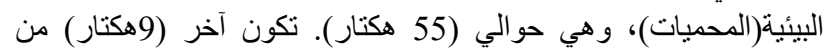

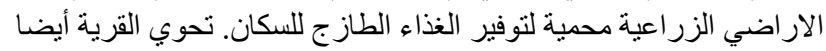

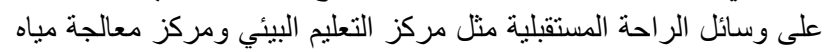

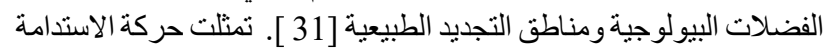

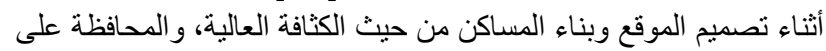

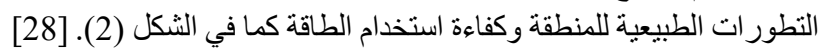

3.1.3

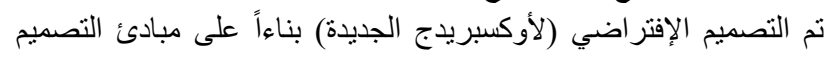

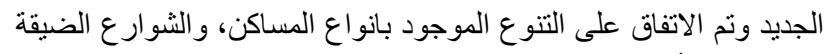

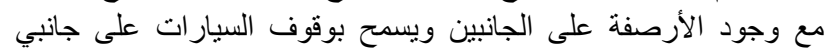

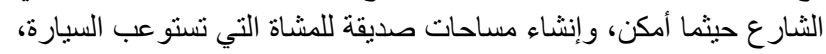

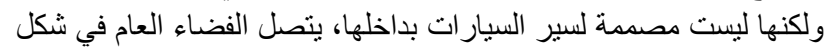

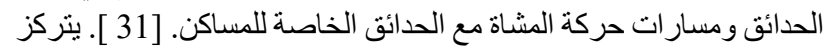

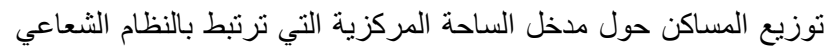

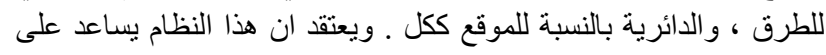

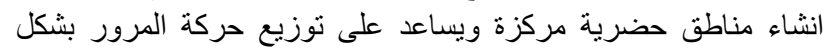

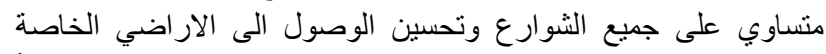

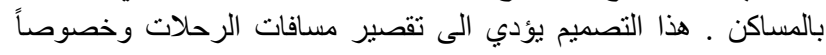

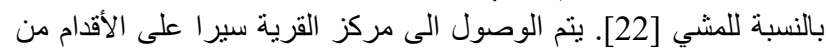

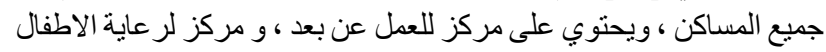

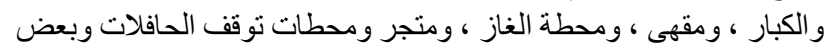

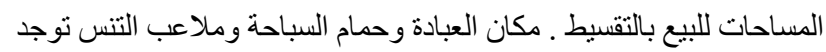

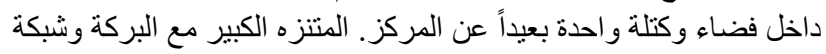

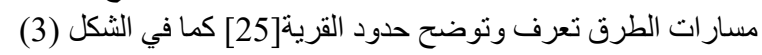

3.1.4 مشروع هضبة روز قدم مقتر ح تطوير روز هيل في العام (1988) ولكنه لم ينفذ بسبب قلة الامو ال

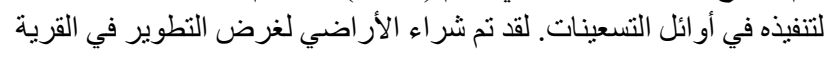

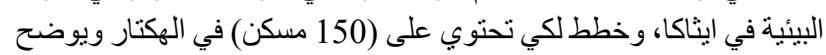


البيئية" (EFA)، يينى المنهجين على قانون الديناميكيا الحراية في

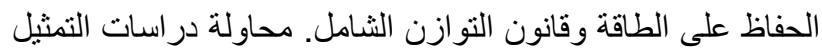

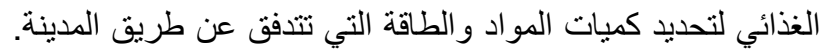
تحليل المواد وطاقة التمثيل الغذائي للقطاعات و الأنشطة داخل التئل المدينة

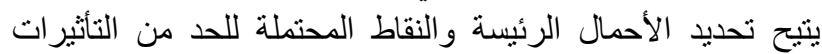

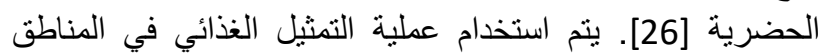

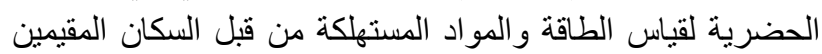

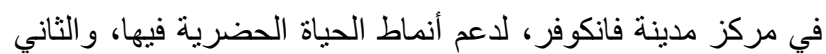

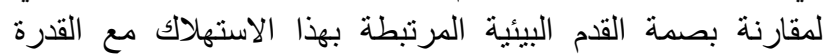

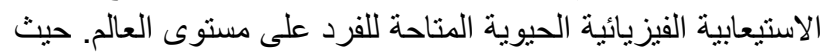

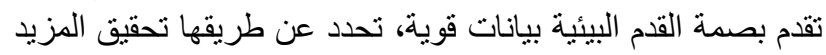

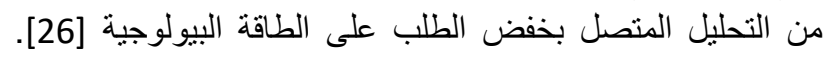

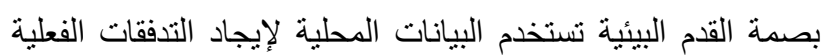

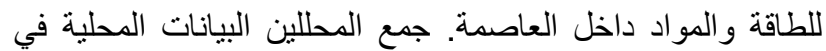

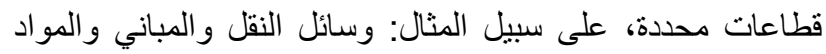

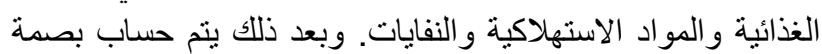

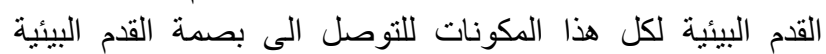

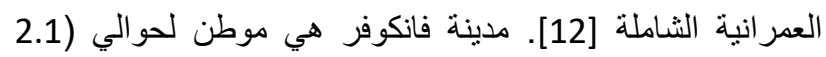

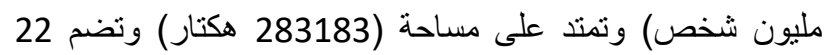

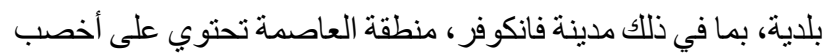

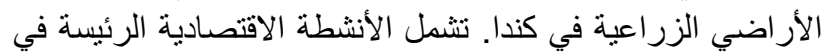

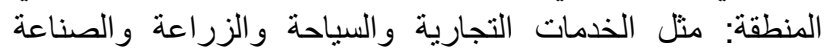

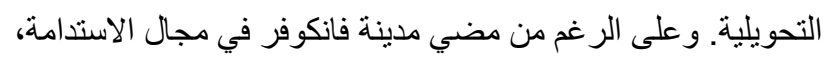

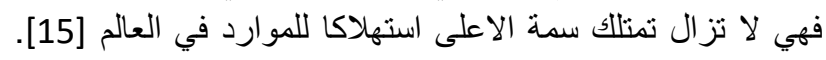

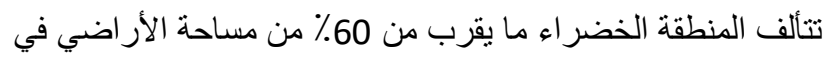

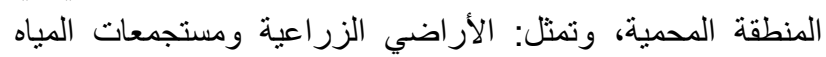

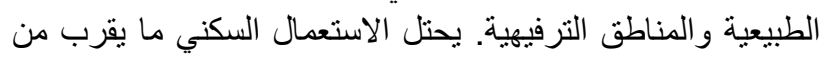

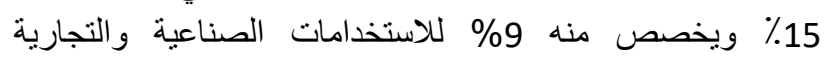

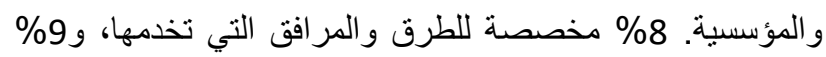

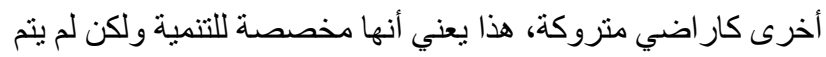

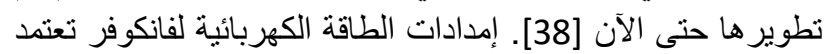

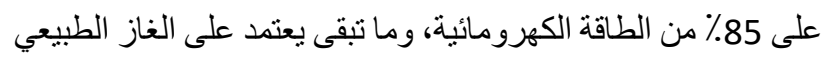

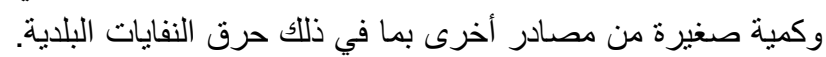

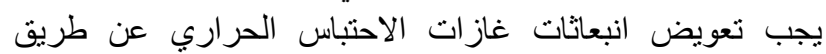

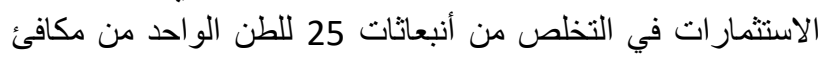
ثاني أكسيد الكربون [15]. كما في الثكل (5).

\subsection{1 بصمة القدم البيئية لمدينة فانكوفر لعام 2006} تتكون بصمة القدم البيئية لددينة فانكوفر من النظم الإيكولوجية لإنية

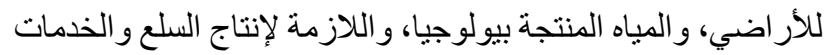

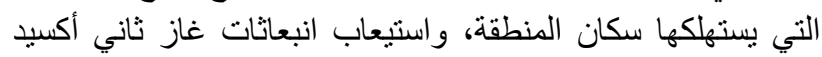

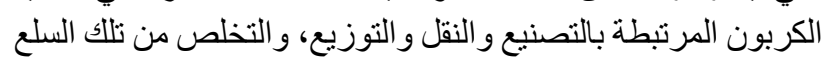

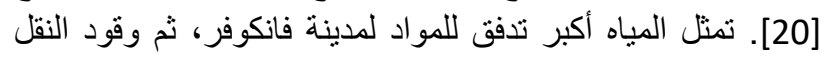

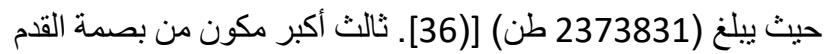

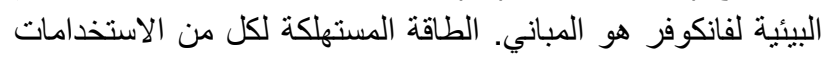

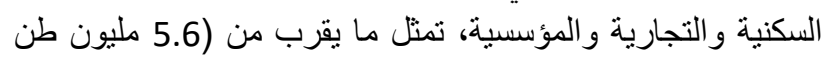

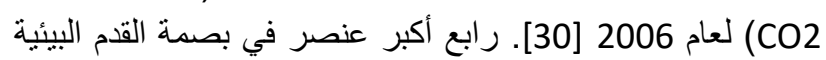

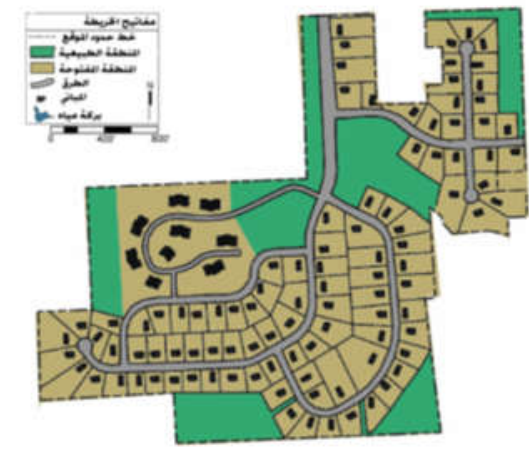

الثكل (4): مخطط تطوير روز هيل [28]

حيث نرى أن مخطط القرية البيئية في ايثاكا محدد في منطقة واحدة،

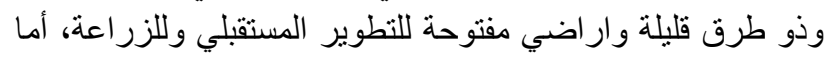

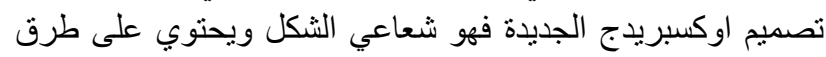

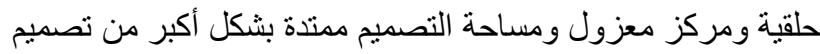

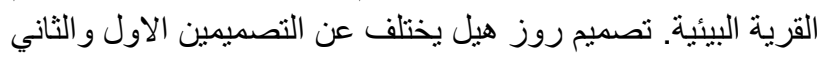

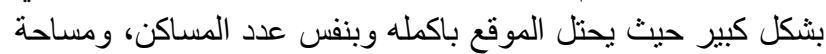
كبيرة للشو ارع، مع عدم وجود مساحة متبقية للنطوير المستقبلي.

3 3.1.6 الكثافة الإجمالية والصافية هي الأعلى بالنسبة للقرية البيئية في إيثاكا وأدنى

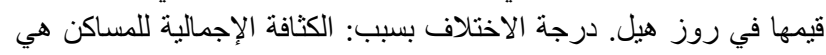

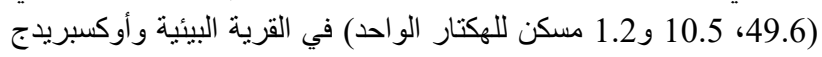

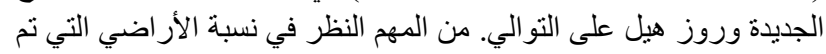

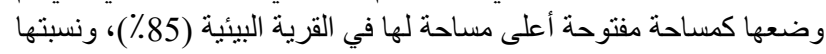

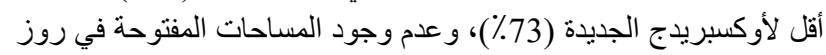

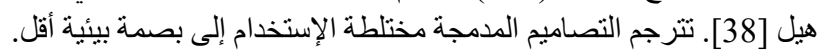

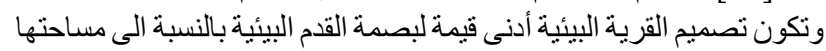

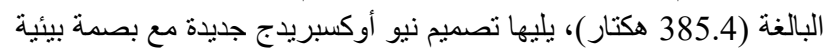

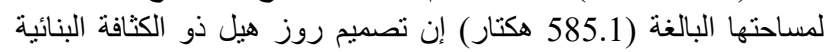

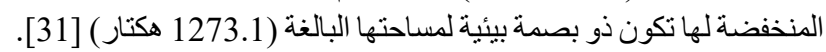

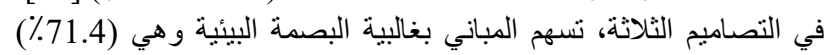

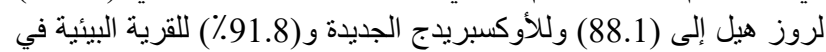

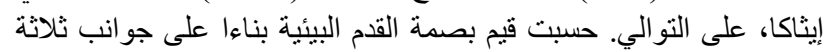

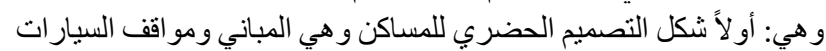

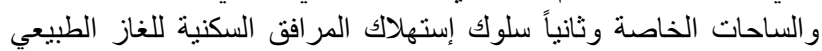

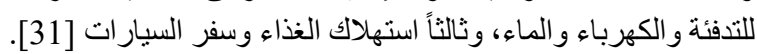

\section{تقييم بصدة القلدم البيئية لمركز مدينة فانكوفر 2013}

يعيش حو الي (350 \% ) من السكان في المر اكز الحضرية في كندا

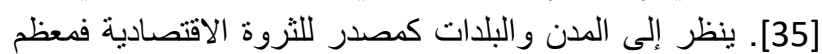

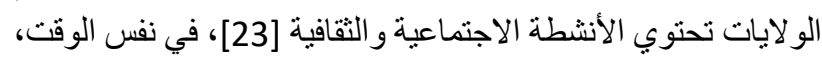

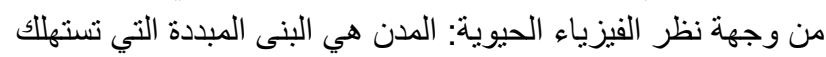

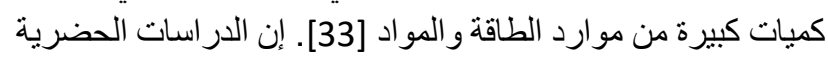

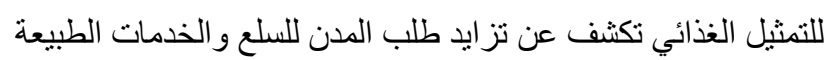

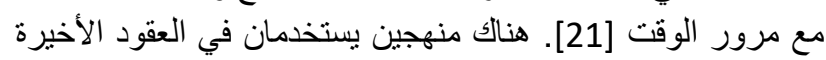

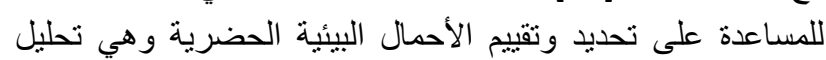

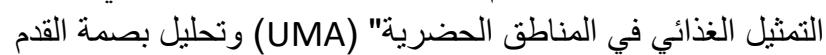




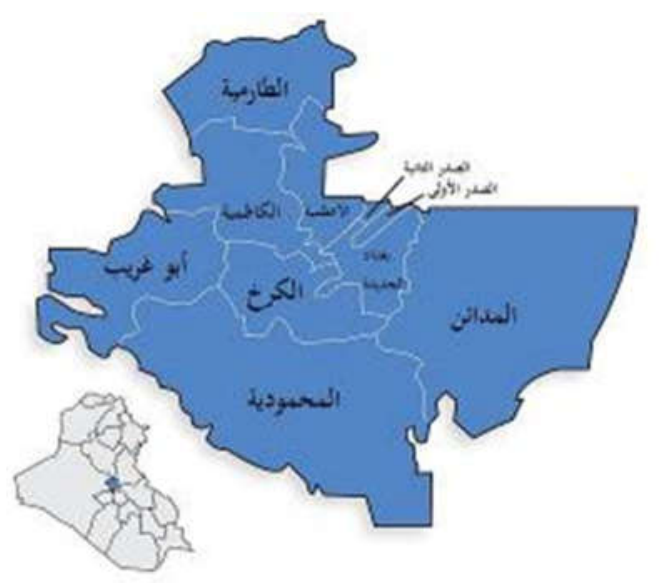

الثكل (6): الحدود الادارية لمحافظة بغداد مع أقضيتها [39]

هي المواد المستهلكة والنفايات. وتشمل المنتجات الاستهلاكية أشياء

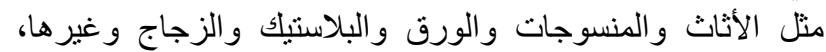

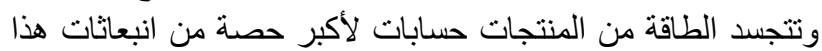

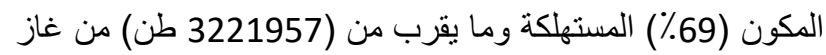

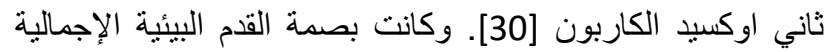

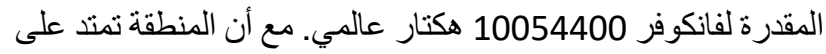

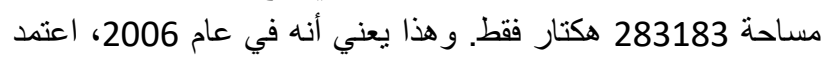

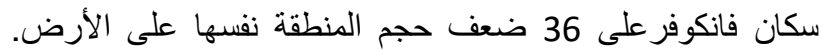
متوسط البصمة البيئية في فانكوفر هي 4.75 هكتار عالمي.

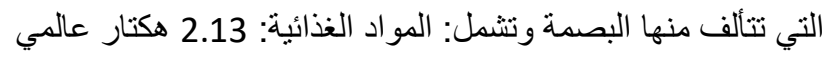

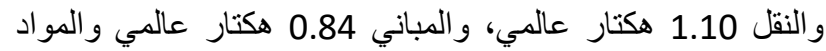
الاستهلاكية 0.68 هكتار عالمي والماء 0.002 هكتار عالمي. [29]

\section{الحالة الدراسية لمدينة بغداد}

تعد مدينة بغداد أصغر مدن العراق بالمساحة، ولكنها تأتي في المرتبة

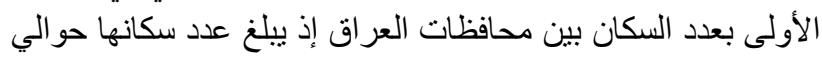
2877888 مليون نسمة أي نسبة 23\% من سكان العان العراق لسنة

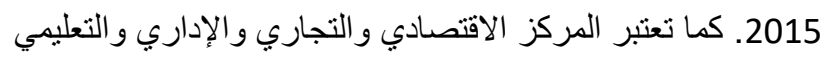

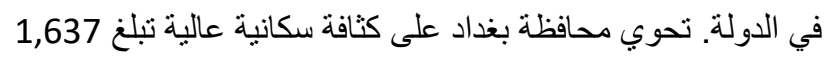

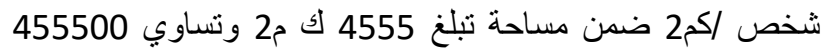

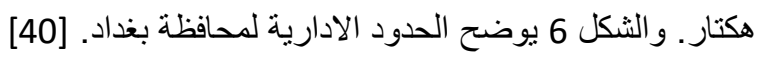

\section{4 $\quad 4.1$}

تبلغ المساحات الزراعية في مدينة بغداد 800,746 ألف دونم من مساحة الار اضي الصالحة للزر اعة البالغة 1, 1,267,314 مليون دونم

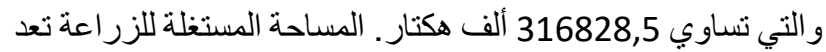

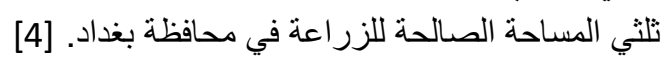
4.2 تبلغ مساحة الغابات في بغداد 30213 هكتار مكونة من الغابات الطبيعية ومساحة البساتين [4]. 4.3 مساحة العياه في بغداد بعد جمع مساحة نهري دجلة و الفرات و القنوات المائية و غير ها تبلغ حو الي بئ 11327.75 هكتار [5]. 4.4 مساحات الرعي في مدينة بغداد

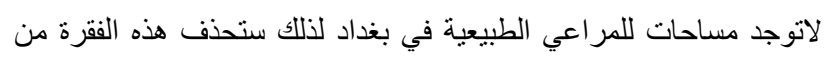
حسابات السعة البيولوجية وبصمة القدم البيئية لاحقاً. [4] لـأل

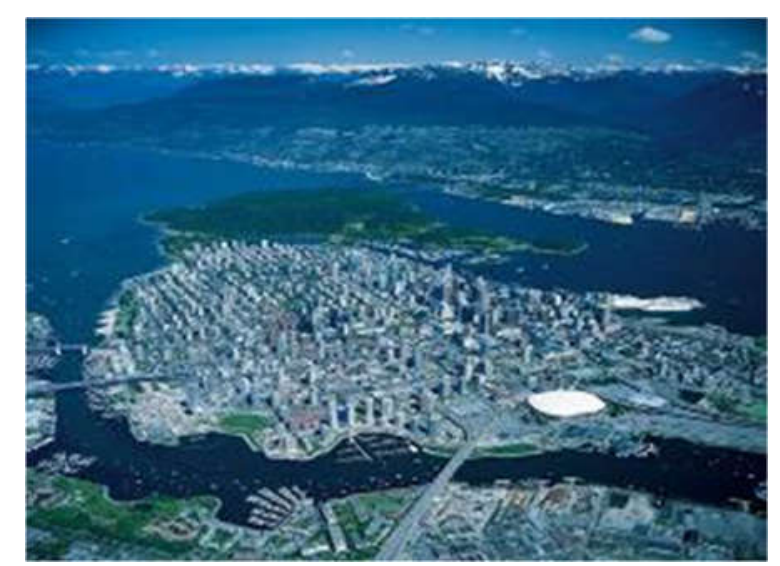

الثكل (5): يوضح مدينة فانكوفر ، وتركز الاستعمال التجاري و السكني

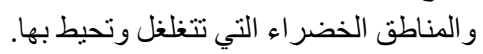

بعد تناول الحالتين الدر اسيتين توصل البحث الى اهم مؤشرات بصمة القدم البيئية في إستدامة المدينة كما في الجدول (3).

جدول (3): مؤشرات الإطار النظري النهائية (إعداد الباحثون)

\begin{tabular}{|c|c|c|}
\hline 2 & 1 & ت \\
\hline انبعانات غاز ثاني & الطاقة فيلاك & الدخخلات \\
\hline 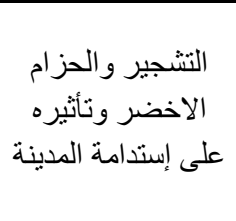 & $\begin{array}{l}\text { إستهلاكة } \\
\text { الطاقة } \\
\text { التنقل }\end{array}$ & 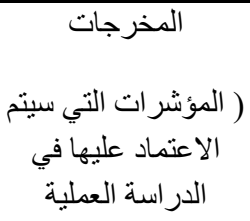 \\
\hline
\end{tabular}




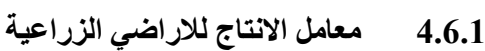

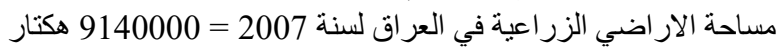

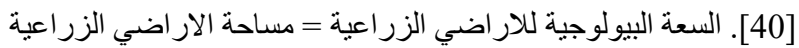

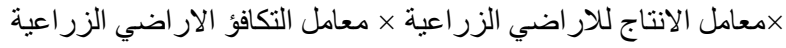
الزراية 0.19 × 29682081 = 2.5140000 × معامل الانتاج للأر اضي الزراعية =) معامل الانتاج للأر اضي الزراعية (YF)

$5639595.39 / 22941400$ معامل الانتاج للأراضي الزراعية (YF) = ميساوي معامل الانتاج

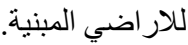

\subsection{2} مساحة الغابات في العراق لسنة $2007=032200$ هكتار [40] السعة البيولوجية للغابات = مساحة الغاباتهمعامل الانتاج لاراضي الغابات xمعامل التكافؤ للغابات

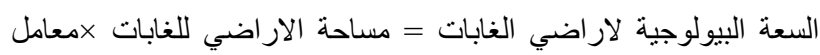

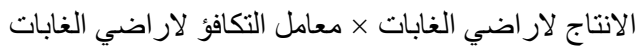

× 0.05

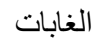

$$
\text { معامل الانتاج لأر اضي الغابات = }
$$

$1048572 / 1484104.05$

$$
\text { (YF) = معامل الانتاج لأر اضي الغابات } 1.41
$$

معامل إنتاج أراضي الغابات = معامل انتاج الكاربون

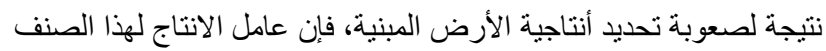

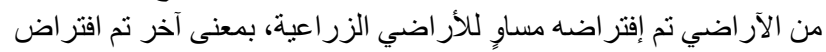

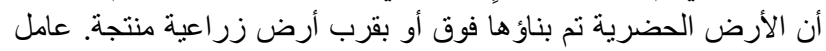

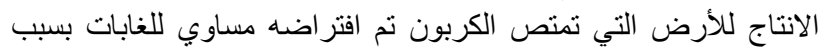

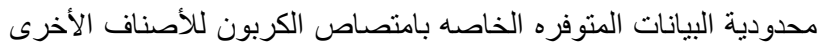

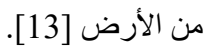

كل كل المساحات المائية داخل البلدان ثم إعطائها عامل انتاج مقداره 1، وذللك

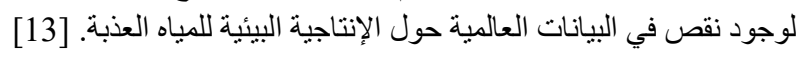

\section{7}

بعد إيجاد معامل الانتاج لمختلف مكونات السعة البيولوجية، سيتم إيجاد

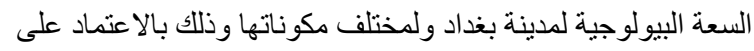
بيانات عام 2015 المتوفرة من الجهاز المركزي للاحصاء وكما يأتي:

$$
\text { - 4.7.1 السعة البيولوجية للاراضي الزراعية }
$$

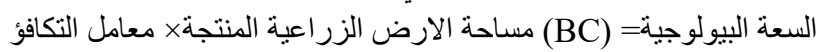

YF معامل الانتاج EQF×

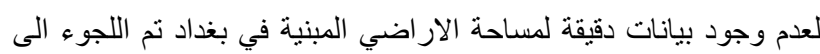

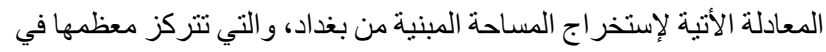

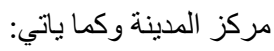

الرساحة المبنية لددينة بغداد = مساحة بغداد الكلية - (مساحة الاراضي الزر اعية + الغابات + المسطحات المائية)

المساحة المبنية لمدينة بغاد = 455500- 4555 (316828.5 + 30213 + 3589.75 $=358369.25-455500=(11327.75$

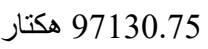

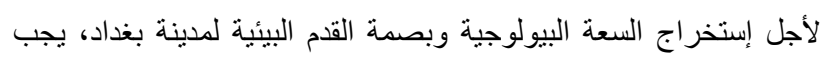

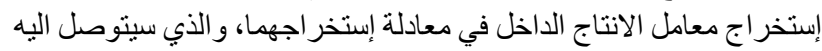

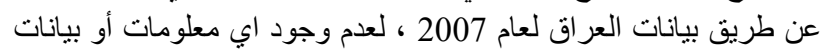

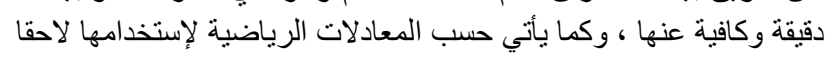
للوصول الى قيم السعة البيولوجية وبصمة القدم البيئية لسنة 2015 : السعة البيولوجية (BC) = مساحة الارض المنتجة A × معامل التكافؤ YF معامل الانتاج EQFx

بصمة القدم البيئية = (كمية المادة المستهلكة سنويا) / (الانتاج السنوي الوطني ل للمادة) × معامل التكافؤ EQF معامل الانتاج

من المعادلتين أعلاه نجد عدم توفر قيم معامل الانتاج لذلك سيتم إستخر اجه

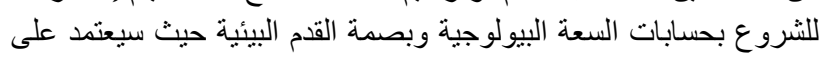

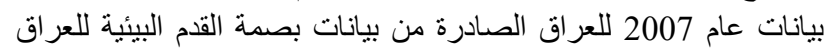

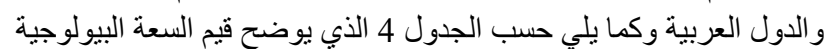

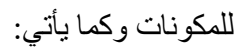

جدول (4): قيم السعة البيولوجية [44]

\begin{tabular}{|c|c|}
\hline 2007 & ألرعة البيولوجية لسنية المحاصيل الزر اعية الغيات \\
\hline 0.19 & \\
\hline 0.05 & \\
\hline
\end{tabular}

معامل التكافؤ لمختلف الاراضي حسب بيانات بصمة القدم البيئية هي ثابتة

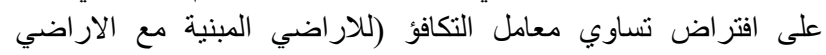
الزراعية) و (ار اضي الغابات مع الكاربون) وحسب الجدول (2).

\section{6 ويصمة القلدم البيئية}

سيتم إستخر اج معامل الانتاج لمختلف الاراضي المكونة للسعة البيولوجية

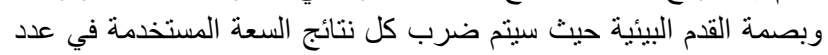

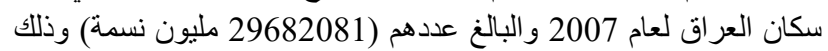
كون قيمة السعة (هكتار / شخص) وكما يأتي [7]: 
جدول (5): السعة البيولوجية لمختلف مكوناتها لمدينة بغداد لعام 2015 (الباحثون)

\begin{tabular}{|c|c|}
\hline السعة البيولوجية & نوع الارض \\
\hline 0.24 & أر اضي الزحاصيل \\
\hline 0.19 & الغابات \\
\hline 0.00053 & ار اضي المياه \\
\hline 0.01 & الار اضي المبنية \\
\hline 0.44 هكتار عالمي & المجموع \\
\hline
\end{tabular}

بصمة القدم البيئية لمدينة بغد/د 4.8

سيتم إستخر اج بصمة القدم البيئية لمختلف مكوناتها عدا أر اضي الرعي حيث

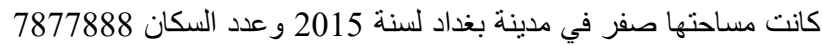
بسبب توفر البيانات الكاملة عنها كما يأتي:

4.8.1

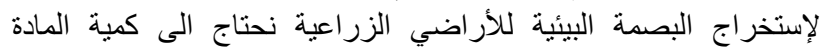

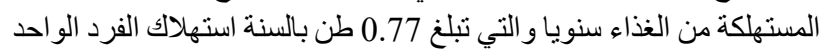

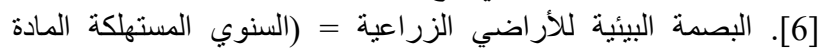

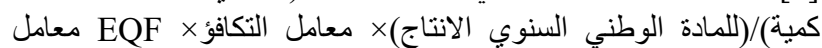

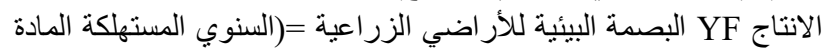

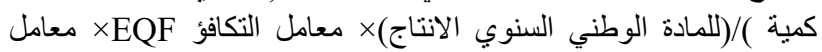

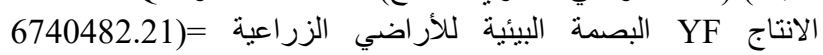

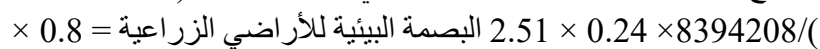
0.24 × 0.48 × 0.48 هكتار عالمي / شخص. 4.8.2 لإستخر اج البصمة البيئية للمياه نحتاج المى كمية المياه المستئهلكة من قبل المبل سكان

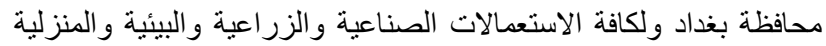

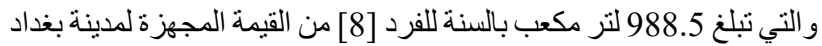

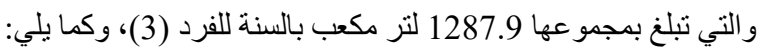
البصمة البيئية للمياه = (السنوية المستهكة المياه كمية) / (السنوية المجهزة المياه كمية) × معامل التكافؤ EQF× معامل الانتاج البصمة البيئية للمياه = (988.5) / 1287.97 × 1 × 1 (9.5 البصمة البيئية للمياه =0.76 × 0.37 × 1 = 0.28 هكتار عالمي / شخص 4.8.3 لإستخراج البصمة للغابات سنعتمد على نسبة الاستهلاك السئل السنوية للفرد

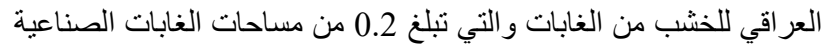
الموجودة فيها وكما يأتي [5]:

البصمة البيئية للغابات = (السنوية المستهلكة المياه كمية) / (السنوية المجهزة المياه كمية) × معامل التكافؤ EQF × معامل الانتاج
السعة البيولوجية للأر اضي الزر اعية = 1908570.488 هكتار تقسم على لقى

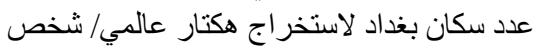
السعة البيولوجية للار اضي الزر اعية = $7877888 / 1908570.488$ السعة البيولوجية للأر اضي الزر اعية = 0.24 هكتار عالمي / شخص 4.7.2

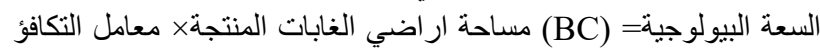
YF معامل الانتاج EQF

السعة البيولوجية لأر اضي الغابات = 1.4261 × 1.260 × السعة البيولوجية لأر اضي الغابات = 1478486.52 هكتار تقسم على عدد

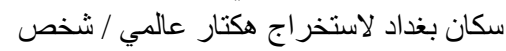
السعة البيولوجية لأر اضي الغابات =

$7877888 / 1478486.52$

السعة البيولوجية لأر اضي الغابات = 0.19 هكتار عالمي /شخص، وتساوي السعة البيولوجية للكاربون.

4.7.3

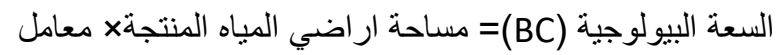
التكافؤ XEQF معامل الانتاج (BF) السعة البيولوجية للمياه = 0.37 × 11327.75 × السعة البيولوجية للمياه = 4191.2675 هكتار تقسم على عدد سكان بغداد لاستخر اج هكتار عالمي السعة البيولوجية للمياه

$7877888 / 4191.2675$

السعة البيولوجية للمياه = 0.00053 هكتار عالمي/ شخص

4.7.4 السعة البيولوجية (BC)= مساحة الار اضي المبنية × معامل التكافؤ EQF

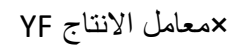
السعة البيولوجية للار اضي المبنية = 07130.75 × 0.24 × 2.51 ( السعة البيولوجية للار اضي المبنية = 58511.56 هكتار تقسم على عدد البكار سكان بغداد لاستخر اج هكتار عالمي / شخص لرس الرس

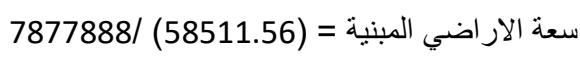
السعة للار اضي المبنية = 0.007 اي تقريبا 0.01 هكتار عالمي / شخص بعد التوصل الى نتائج مختلف مكونات السعة البيولوجية لمدينة بغداد لعام 2015 سيتم تنظيمها كما في الجدول (5): 
البصمة البيئية للأرض المبنية للفرد الو احد = (الكلية البيئية البصمة) / (الكلي

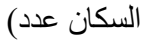

البصمة البيئية للأرض المبنية للفرد الو احد = (1099380) / البصمة البيئية للأرض المبنية للفرد الواحد = 0.14 هكتار عالمي / شخص بعد إستخر اج بصمة القدم البيئية لمختلف مكوناتها ستتظم بالجدول 6 للتوصل الى بصمة القدم البيئية الكلية لمدينة بغداد وكما يلي:

جدول (6): بصمة القدم البيئية لمختلف مكوناتها لمدينة بغداد 2015 (الباحثون)

\begin{tabular}{|c|c|c|}
\hline السعة البيولوجية & البصمة البيئية & نوع الارض \\
\hline 0.24 & 0.48 & أر اضي الزحاصبيل \\
\hline 0.19 & 0.35 & الغابات \\
\hline 0.00053 & 0.28 & ار اضي المياه \\
\hline- & 3.052 & الكاربون \\
\hline 0.01 & 0.14 & الار اضي المبنية \\
\hline عالمي/شخص 0.44 هكتار & عالمي/شخص 4.3 هكتار & المجموع \\
\hline
\end{tabular}

لذللك تكون بصمة القدم البيئية لمدينة بغداد 4.3 هكتار بينما سعتها البيولوجية حوالي 0.44 هكتار عالمي/شخص لذلك يكون العجز البيئي لمدينة بغداد : العجز البيئي لمدينة بغداد = السعة البيولوجية - بصمة القدم البيئية العجز البيئي لمدينة بغداد = 0.44 - 4.3 = - 3.86 هكتار عالمي/شخص البئي مقدار العجز البيئي لمدينة بغداد لئئ بغداد

\section{5. سيتم معالجة جزء من العجز البيئي عن طريق}

\section{1}

كشفت بيانات حكومية اصدر ها الجهاز المركزي للاحصاء التابع لوزارة

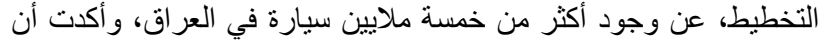

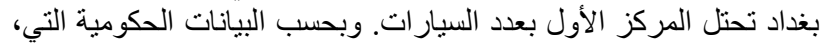

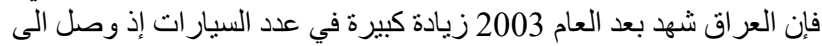

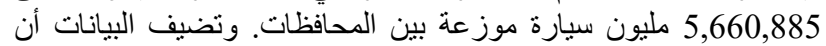

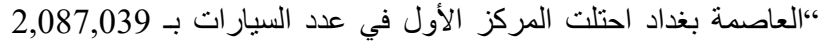

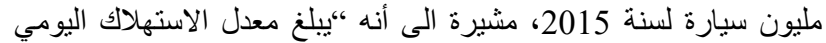

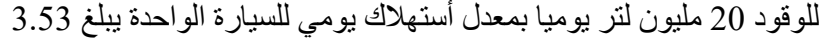

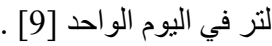

$$
\text { الطن المتري لغاز × CO2 = } 0.000002 \text { لتر × } 365 \text { يوم }
$$$$
\text { الطن المتري لغاز } 365 \text { × } 3.52=0.000002 \text { × }
$$

البصمة البيئية للغابات = 0.2 × 1.26 × البصمة البيئية للغابات =0.35 هكتار عالمي / شخص 4.8.4 بصمة القدم البيئية للكاربون

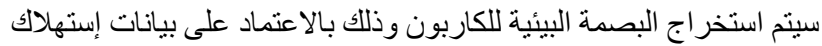
البنك الدولي للفرد العر اقي من الكاربون والتي تبلغ نسبتها 5.15 طن متربي

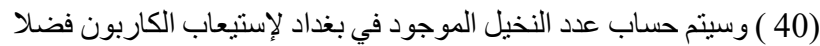

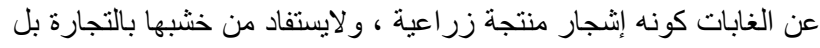

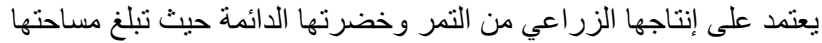
في بغداد 421,75 هكتار بالاضافة الى مساحة الغابات البالغة 832200

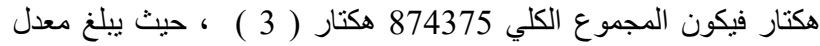

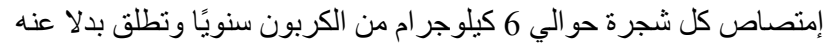

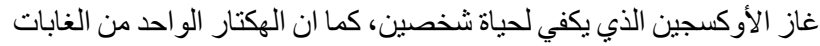

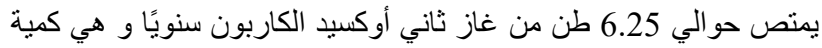

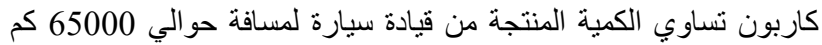
وكما يأتي : وان نهان

كمية الكاربون المنبعثة السنوية = كمية الكاربون السنوية المنبعثة من الفرد

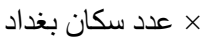

كمية الكاربون الممتصة السنوية = كمية الكاربون السنوية الممتصة من الهكتار الواحد × المساحة الكلية

البصمة البيئية للكاربون = (السنة في المنبعثة الكاربون غاز كمية) / (السنة الكاجة

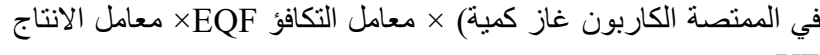

البصمة البيئية للكاربون = (5.15 × 8.25 (8753873) × (874375) ×

$1 \times 0.37$

البصمة البيئية للكاربون = 3.052 هكتار عالمي/ شخص

4.8.5

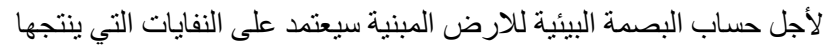

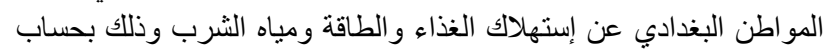

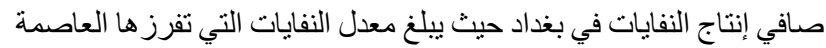

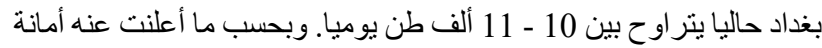

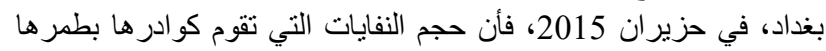
صحيا تبلغ 7000 طن يوميا، هذا يعني أن نحو

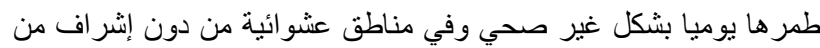

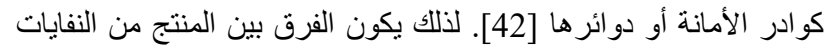

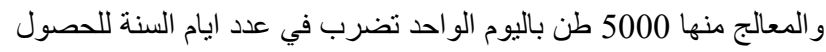
على نسبتها السنوية وكما يأتي:

نفايات مدينة بغداد غير المعالجة السنوية = 5000 × 365 = 1825000 طن بالسنة

البصمة البيئية للأرض المبنية = (السنوية غير المعالجة النفايات كمية)

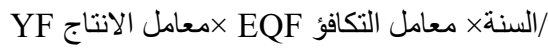
البصمة البيئية للأرض المبنية = 2.51 × 0.24000 × البصمة البيئية للأرض المبنية = 1099380 هكتار عالمي لمدينة بغداد 
الاستنتاجات

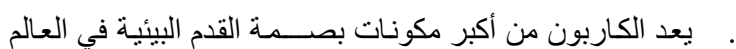

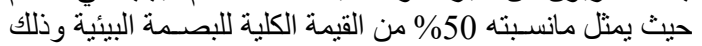

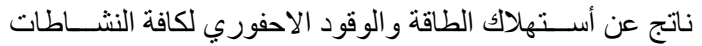

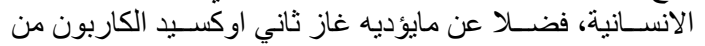

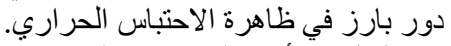

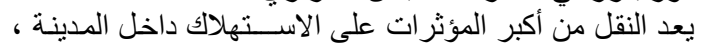

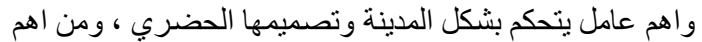

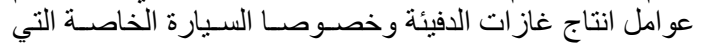

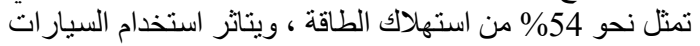

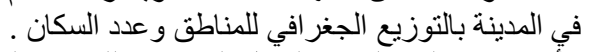

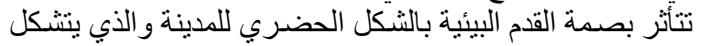

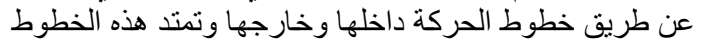

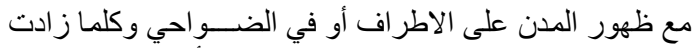

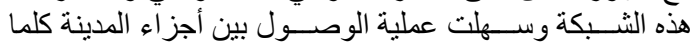
زادت كفاءة إستخدام وسائط النقل وبالتالي تقليل البودي البصمة البيئية.

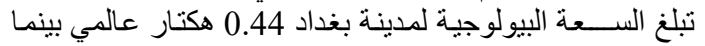

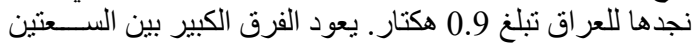

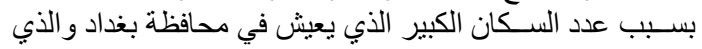

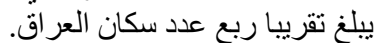

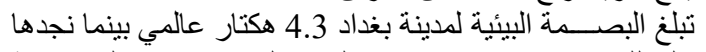

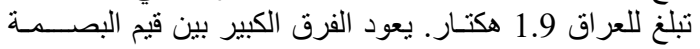

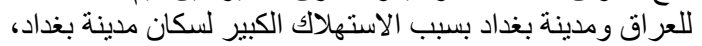

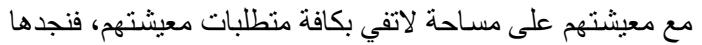

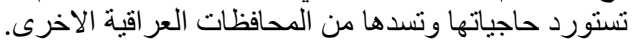

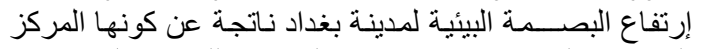

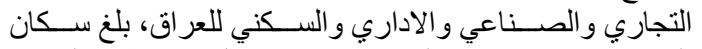
العاصمة حسب وز ارة التخطيط بالاستناد الى إسقاطات لإن السكان

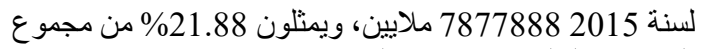

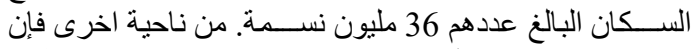

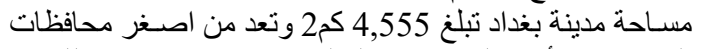

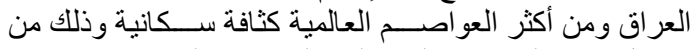

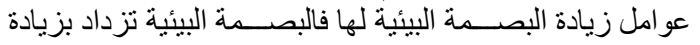
عدد السكان كونها إنعكاسا لنشاطاتهم الاستهلاكية.

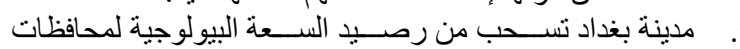
العر اق الاخرى، لتحقيق رغبات العيش لساكنيها.

التوصيات

1. يوصـي البحث بالتوسع بالدر اسـات الخاصـة بيصـمة القدم البيئية

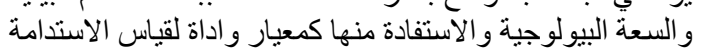

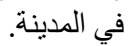

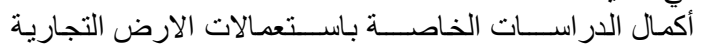

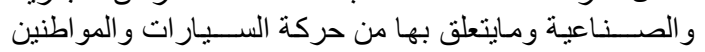

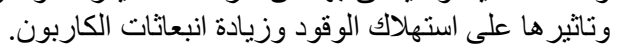

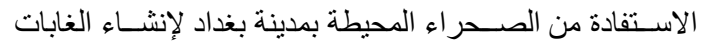

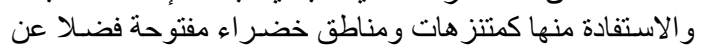

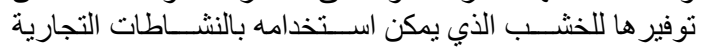
الداخلية.

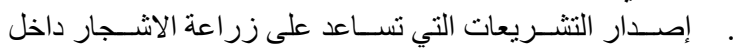

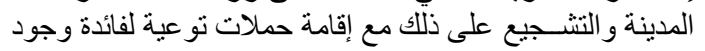
الاشجار و المناطق الخضر على ذلاء داخل المدينة.

المصادر

[1] الامم المتحدة، المجلس الاقتصـادي والاجتماعي، تسخير العلم و التكنولوجيا

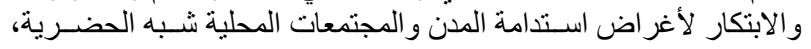

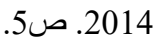

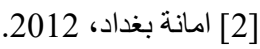

الطن المنري لغاز CO2 = 0.0026 طن معدل إنتاج السيارة السنوي في

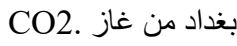

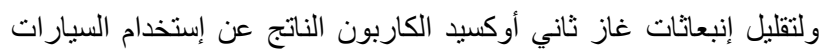

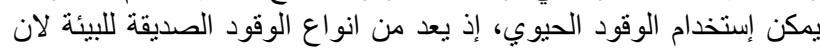

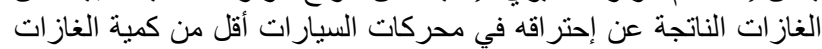

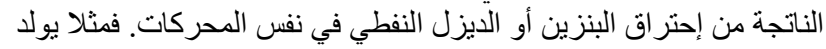

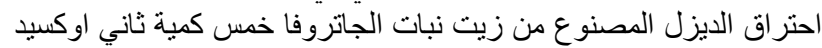

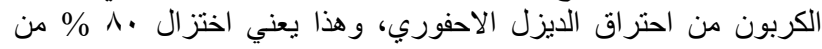

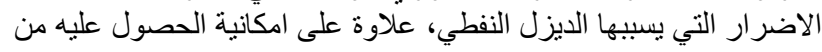

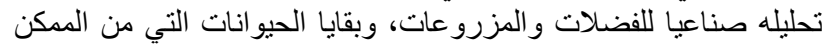

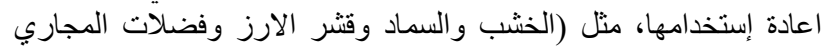

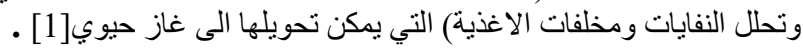

$$
\text { التشجير والحزام الاخضر وتأثيره على إستد/مة المدينة }
$$

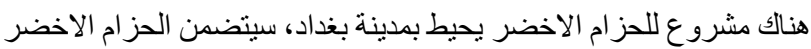

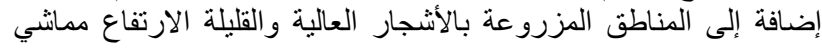

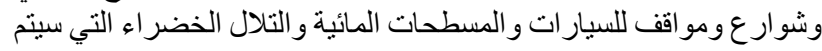

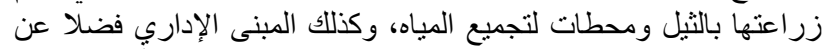

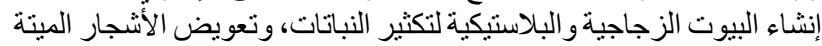

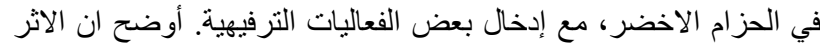

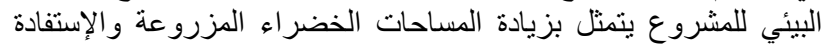

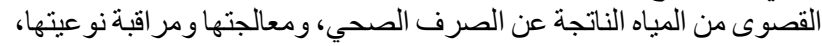

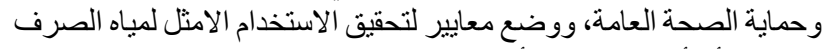

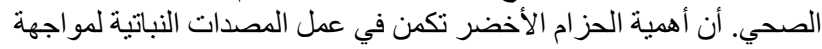

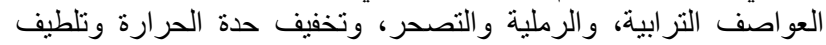

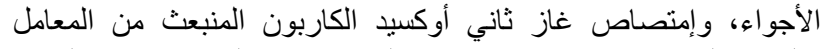

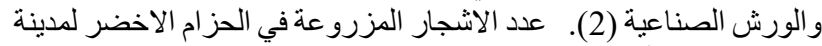

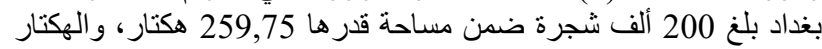

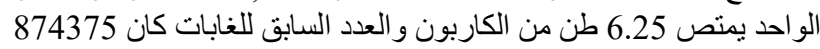

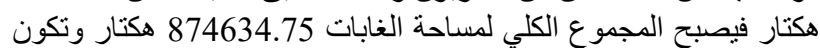

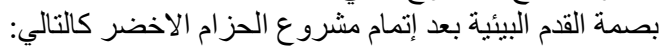

البصمة البيئية للكاربون = (السنة في المنبعثة الكاربون غاز كمية) / (السنة المبنة

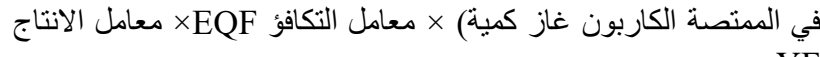

YF

كمية غاز الكاربون المنبعث من المواطن العراقي تبلغ 5.15 طن بضرب

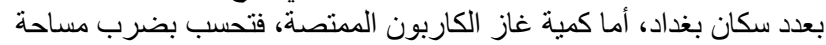

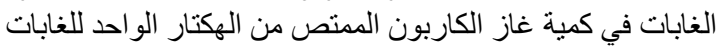

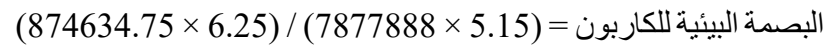
$1 \times 0.37 \times$

البصمة البيئية للكاربون = 3.051 هكتار بينما كانت البصمة البيئية قبل هذا

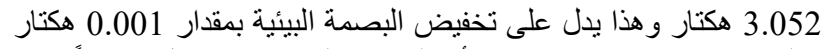

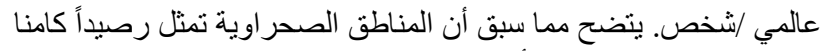

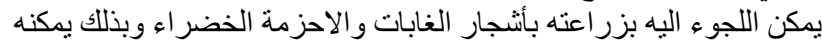

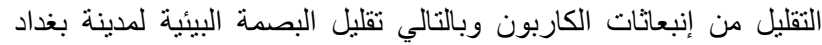

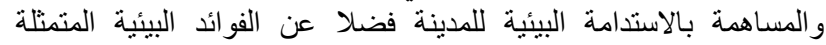

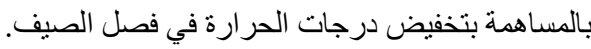


[27] Landesman, S. A new twist on the American dream theme: the birth of the first cohousing model site, The Ithaca Journal, 4 October 1997. P. 6/7.

[28] Meltzer, G. Cohousing: verifying the importance of community in the application of environmentalism, Journal of Architectural and Planning Research, 17(2), 2000 .p110

[29] Metro-vancouver Regional District, Updated 2007 Community Energy and Emissions Inventory. Province of British Columbia, Victoria BC. June 16, 2010.

[30] Metro Vancouver. Recycling and Solid Waste Management 2006 Report. Greater Vancouver Sewerage and Drainage District, Burnaby BC.2006.

[31] MOOS MARKUS, WHITFIELD JASON, JOHNSON LAURA \& ANDREY JEAN, Does Design Matter? The Ecological Footprint as a Planning Tool at the Local Level, Journal of Urban Design, Vol. 11. No. 2, 2006, p1/6/7/9/12/13/17.

[32] Rees, W., Eco-footprint analysis: merits and brickbats, Ecological Economics, 32(3), 2000 .p/73/74/371.

[33] Rees, W.E., 2011. Getting serious about urban sustainability: eco-footprints and the vulnerability of twenty-first-century cities (Chapter 5). In: Bunting, T., Filion, P., Walker, R. (Eds.), Canadian Cities in Transition: New Directions in the Twentyfirst Century. Oxford University Press, Toronto, pp. $70 / 121$

[34] Rees, W.E., The ecological crisis and self-delusion: implications for the building sector. Building Research and Information 37 (3), 2009 .p300.

[35] Statistics Canada. Census Data: Community Profiles. Vancouver, British Columbia (Census Metropolitan Area). 2006b.

[36] Statistics Canada, Food Statistics 2006 Catalog No. 21-020-X.2007.

[37] Wackernagel, M., Deumling, D., Manfreda, C. \&Dholakia, R. Assessing Your Household's Ecological Footprint, Version 3.2, Redefining Progress.2003.

[38] Walker, L. \& Rees, W. (1997) Urban density and ecological footprints: an analysis of Canadian households, in: M. Roseland (Ed.) Eco-City Dimensions, (Gabriola Island, BC: New Society Publishers).1997. p96.

[39] ( قاقضية العراقhttps://ar.wikipedia.org/wiki/)

[40] https://data.albankaldawli.org/indicator/AG.LND.F RST.K2?locations $=I Q \&$ name desc $=$ true

[41] http://www.almadapress.com/ar/news/74441-بغداد/2/ تخلف-11/ألف_طن-من_النفايات_يو//2r/di .

[42] http://www.sandroses.com/gal/displayimage.php?pi $\mathrm{d}=11982$

[43] www.footprintnetwork.org.Result from National Footprint Account, 2010.

$$
\begin{aligned}
& \text { [3] التقرير البيئي، الجهـاز المركزي للأحصــــاء، وزارة التخطيط، العراق، } \\
& \text { الفصل الثالث، 2014. ص83. } \\
& \text { [4] التقرير الســوي البيئي الصــادر عن الجهاز المركزي للأحصـاء، الفصـل } \\
& \text { الخامس،2015. } \\
& \text { [5] التقرير الســنـوي للتنميـة الزراعيـة في الوطن العربي، المنظمة العربيـة }
\end{aligned}
$$

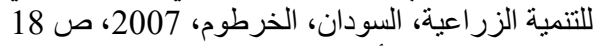

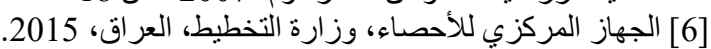

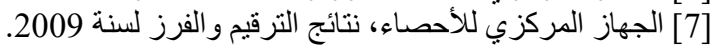

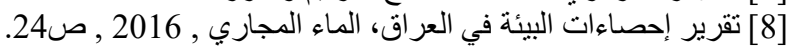

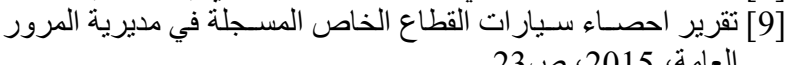

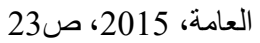

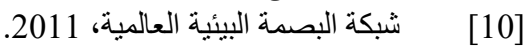

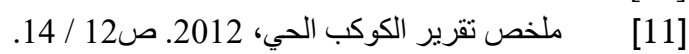

\section{Refrences}

[12] Barrett, J. Component ecological footprint: developing sustainable scenarios. Impact Assessment and Project Appraisal 19 (2), 2001 .p 107.

[13] Brad Ewing \& othersk, Calculation Methodology for the National Footprint Accounts, 2010 .p3/4/5/6 /8.

[14] Berelowitz, L., Dream City: Vancouver and the Global Imagination. Douglas and McIntyre, Vancouver BC.2005.

[15] British Columbia (The Province of), Carbon Neutral BC, a First for North America. News Release 2011ENV0032e000805, 2011.

[16] Browne, D., O’Regan, B., Moles, R. Material flow accounting in an Irish cityregion 1992e2002. Journal of Cleaner Production 19, 2011. p 967.

[17] Chambers, N., Simmons, C. \&Wackernagel, M. Sharing Nature's Interest: Ecological Footprints as an Indicator of Sustainability (London: Earthscan), 2000.

[18] ECOLOGICAL FOOTPRINT ATLAS, 2010 .p2/9/10/12/22/23.

[19] Ewing, B., Goldfinger, S., Oursler, A., Reed, A., Moore, D., Wackernagel, M. The Ecological Footprint Atlas 2009. Global Footprint Network, Oakland, CA.2009.

[20] FAO (United Nations Food and Agriculture Organization). FAOSTAT: Production: Crops.2010.

[21] Folch, R., Paris, A., Socioecologia i gestio' ambiental a l'a'Reade Barcelona. Revista Econo'mica de Catalunya 34, 1998. p52

[22] Hall, K. \& Porterfield, G. (2001) Community by Design: New Urbanism for Suburbs and Small Communities (New York: McGraw-Hill). 2001.

[23] Hough, M. Cities and Natural Process (London: Routledge). 1995.

[24] Jacobs, J., Cities and the Wealth of Nations. Vintage Books, New York.1984.

[25] Johnson, L. C. From hybrid housing to cybrid neighborhoods: case studies of five decentralized tele-workspaces, Journal of Architectural and Planning Research, 20(2), 2003. pp. 136.

[26] Kennedy, C., Cuddihy, J., Engel-Yan, J. The changing metabolism of cities. Journal of Industrial Ecology 11 (2), 2007. P 43/159. 


\title{
Ecological Footprint and Sustainability of Baghdad City
}

\author{
Zeyad Ali Ismael 1,", Saba Jabbar Nemaa ${ }^{2}$, and Jathwa Abd-Al Kareem Ibrahem ${ }^{3}$ \\ ${ }^{1}$ Department of Urban Planning, University of Kufa, Kufa, Iraq, zyadas@uokufa.edu.iq
}

${ }^{2}$ Department of Architecture Engineering, University of Baghdad, Iraq, dr.saba_alkhafaji@yahoo.com

${ }^{3}$ Department of Architecture Engineering, University of Baghdad, Baghdad, Iraq, jathwa58@yahoo.com

*Corresponding Author: Zeyad Ali Ismael,email: zyadas@uokufa.edu.iq

Published online: 31 August 2019

Abstract - The city of Baghdad suffers from horizontal expansion resulting from the large increase in population, and the consequent increase in the demand for energy and food and increase the introduction of carbon dioxide. Therefore, Baghdad has become overcrowded and suffers from bottlenecks, especially in the city center, resulting in design problems, poor infrastructure and lack of accounts for energy consumption or the amount of renewable energy produced. Due to the lack of research and studies that dealt with this subject, the research problem of (the scientific need to reach the elements of the ecological footprint that leads to the sustainability of Baghdad city) resulted in the research hypothesis that the ecological footprint has an impact on the sustainability of the city of Baghdad. The research has identified the following objectives: To study, understand and provide scientific knowledge about the ecological footprint with its various components. As well as access to the ecological footprint and biological capacity and its impact on the sustainability of the city of Baghdad. This will be addressed through a study of the ecological footprint, its components and components, and the study of some global examples of the applications of ecological footprint in the sustainability of the city, ending with fingerprinting and the biological capacity of Baghdad city and the practical application of ecological footprint indicators in Baghdad city sustainability.

Keywords - Ecological footprint, biological capacity, environmental deficit, sustainable consumption. 